\title{
Teaching Thinking on Jewelry Design Major in Colleges and Universities
}

\author{
Fu Zhang* \\ Department of Public Art, Academy of Arts, Shenyang University, Shenyang, Liaoning, China \\ *Corresponding Author email: 1873613946@qq.com
}

Keywords: jewelry design; professional teaching; colleges and universities

\begin{abstract}
All countries advocate indigenous spirit, seek the road suitable for national development, and advocate the spirit of local spirit, self-consistent, but an effective continuation of the development of national design. The future development direction of Chinese art jewelry also cannot be separated from the traditional foundation of our nation. In this respect, it is necessary to learn from Italy and Japan. Japan also has a similar development process. After the Meiji Restoration, Japan has been pursuing internationalization and modernization. Later, it has also found that the only westernization of the simple Westernization has dissimilated the things of their own nation. Later, the whole nation began to reflect on Japan's traditional culture, looking for Japanese unique materials and techniques, such as the use of lacquer and the revival of wood grain metal technology. Tomomi, a Japanese designer, has stepped out of a road of Oriental Development rooted in national culture. It includes visual purity, formal consistency and material technology, which in turn affects the jewelry art in Europe and America.
\end{abstract}

\section{Introduction}

Jewelry, as one of the various kinds of human ornaments, is a special carrier of human emotion and culture due to its characteristics of "zero distance" contact with humans [1]. The design and production of Chinese jewelry has a very glorious historical period [2]. Among the treasures left over from countless history, we feel the noble and noble taste of the ancient art [3]. The love of ornaments and the pursuit of beauty are innate, as Gombrich said: "the charm of decoration is that it can change objects without changing objects"[4]. This change is not merely a change in form. It is also a new qualitative change, which is generally manifested by the satisfaction of material and spiritual demands of human beings [5]. The desire for the acquisition of new qualities makes the design of beauty a spiritual creation that transcends functional and practical factors [6].

Jewelry in ancient China is often associated with wealth and status. In the long history of jewelry culture, the ornamental function of jewelry has a great influence. Heavy history makes jewelry become a unique cultural carrier [7-9].

Any design material has its own way of blooming or spreading. How to display its most beautiful appearance is a very challenging thing. In the process of creation, it is also a process of continuous dialogue with him. You should treat it with respect and gentleness. Otherwise, it will not show its beauty, or give up your communication with you.

The strengthening of global internationalization does not make the design of various countries standardized, nor does it mean that the styles of different nationalities will be unified. All countries advocate indigenous spirit, seek the road suitable for national development, and advocate the spirit of local spirit, nor is it self consistent, but an effective continuation of the development of national design. The future development direction of Chinese art jewelry also can not be separated from the traditional foundation of our nation. In this respect, Italy and Japan have much to learn from.

\section{Research Progress of Modern Foreign Design}

Italy's modern design has also experienced arts and crafts like "Arts and crafts" and "new art". But with its profound artistic tradition and innovative consciousness, Italy has not been bound by popular fashions in Europe. Italy has not deliberately revived the classical design of jewelry, its 
jewelry design has distinct national characteristics. Most of them originate from the internal characteristics of national culture, rather than simple details or symbols. Italy is the world's largest producer and export of jewelry, producing more than 1/4 of the world's output and exports. The International Jewellery Fair, held in Vicenza, Italy every spring, is one of the most important jewelry exhibitions in the world. Japan has a similar development process. Japan has been pursuing internationalization and modernization since the Meiji Restoration. Later, it was found that Westernization merely alienated the things of its own people. Later, the whole nation began to reflect on Japan's traditional culture and find unique materials and techniques in Japan. For example, the use of lacquer and the revival of grained metal technology (as shown in Figures 1 and 2), a collar made by Japanese designer Tomomi Matsunage was made of bamboo chips. The bamboo slices, treated with special processes, fit the curve of the neck. After a thin piece of bamboo is polished and painted, it is more beautiful in shape and material than in ordinary Jewels (Figure 3). Japan has gone out of an oriental mode of development, which is rooted in the culture of the nation, including the pure visual, formal and material technology, which in turn affects the art of jewellery in Europe and America. This attitude has many of our previous cultures, and then gradually disappeared.
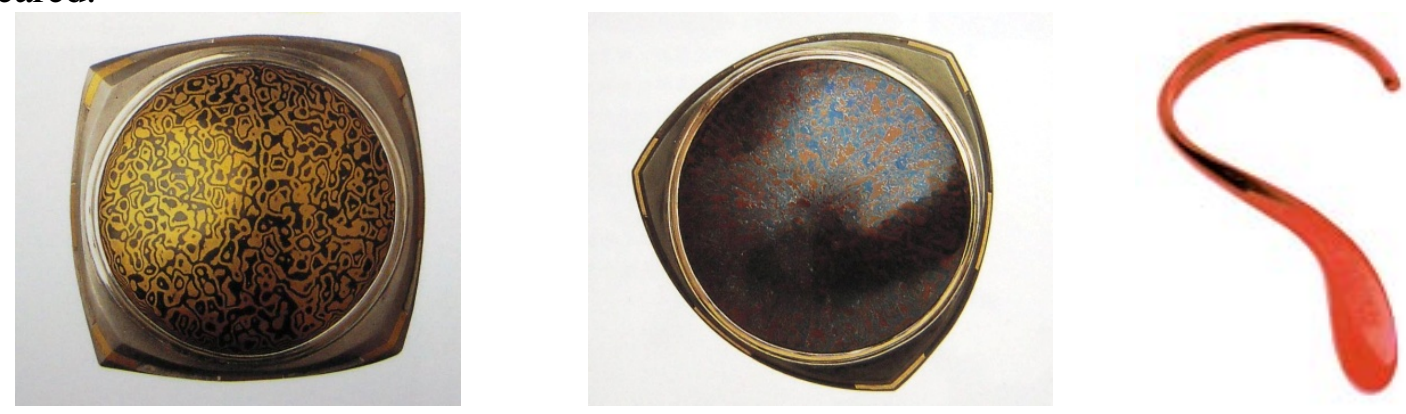

Figure 1, 2 Wood ring metal ring Figure 3 Tomomi Matsunage collars, bamboo and lacquer

We can also refer to the characteristics of nationalization in the field of clothing. The Japanese costume designer, Lssey Miyake, integrated the Zen charm into the design of the East. The clothes he designed fully absorbed the experience of cutting and organization in the Japanese kimono. He applied traditional hanging, wrapping, winding and folding to his design, creating countless possibilities between his body and his clothes. Drawing on the traditional Japanese method of plane cutting, he tried to return the clothes to a piece of square cloth, because it is the basic element of clothing. Yamamoto Teruji combines the special innovation with the classics perfectly, wandering between the age and the culture. He disdain the old ideas that stressed the lines of women since twentieth Century, advocating the use of hanging and parcels to dress up women, thinking that the texture of the fabric and the style of the loose fitting body are more important. His works have a strong personal style, while maintaining the color and aesthetic characteristics of traditional Japanese clothing. In the eyes of Westerners, it is a typical Japanese costume, but in the eyes of the Japanese, it is very avant-garde and bold design.

\section{Chinese Local Art Practice}

Nowadays, more and more local artists and designers are also rooted in the creative expression of national ways. Marco, the national inheritor of the metal filaments, Bai Jingyi, the "exception" and "useless" founder, applied the Oriental elements into the costume design. The origin of the "useless" brand name is based on her deep understanding of traditional culture. She went into the folk alleys and remote villages, looking for all kinds of hand craftsmanship, including weaving, dyeing, sewing and craftsmen. Then she decided to save the "useless" things they all thought of themselves - not in the museum, but in the life of the city. You can't find any traditional patterns or symbols on her clothes, but you can still feel the strong Chinese elements in it. More traditional expressions and cultures are conveyed in clothing, rather than simply "transplantation". Her works reveal the ancient tradition of Chinese art pursuit of the "big voice sound thin, clumsy, great form is 
beyond shape" the mood. The spread is the implicit and introverted beauty of the Oriental women.

As a representative of Chinese artists in the world, Cai Guoqiang is also a successful application of national elements. He once said: "there is a desire to show the tradition in all people". This should be a kind of cultural consciousness that human beings have. His consciousness is fully revealed in his works, the flavor and brand of a strong Chinese painting. He pays great attention to material matters, and tends to do so without delay. He used traditional materials and aesthetics to express emotions, and created various links between different clues and traditional culture in his works. Cai Guoqiang's hometown, Quanzhou, has a very strong folk culture atmosphere. The simple and exquisite handicraft tradition has brought natural inspiration to his art making craft. He flexibly treats the tradition and says, "the nation is not necessarily the world." National things also need to be opened to the world, there is a process of language translation, and more needs to be introduced to the world. He did not look at tradition in an upward manner. He said: "this is an era without authority." The interconnectivity and crossover of art enable us to find the direction of the development of Chinese art jewelry from these successful artists.

To develop healthy and sustainable jewelry, there must be a market and a corresponding consumer group. Whether jewelry artists or designers should have a clearer design orientation for their works, a clear positioning can form a specific consumer group for the market. Help and promote consumers to choose their own age, identity, occupation, wear the environment and a series of factors suitable for my jewelry. Highlight the wearer's temperament rather than become the "mobile display rack" of goods. The clear positioning of design can also get rid of the current trend of business and consumers in the Chinese market, and lack of blind production and consumption of measurement and judgement.

\section{The Role of the Cultivation of Consumer Market in Jewelry Design}

The training of the consumer market plays a vital role in the design of Chinese art jewelry and even the design of the whole nation. I have visited many large counters and exhibition venues in Guangzhou and Shenzhen. The vast majority of consumers are unwilling to pay higher fees for the personalized design of jewelry, but the brand value added is relatively high. More consumers are willing to buy gold jewels in reputable stores, although the prices of these stores are relatively high, but the good reputation makes the buyers feel relieved (like Figure 4). But for some very personal jewelry designs, most buyers are "pioneer consumers", those who emphasize individuality and fashion. They focus on leading the avant-garde image, putting style design as the top priority and price setting. These are all good starting points.

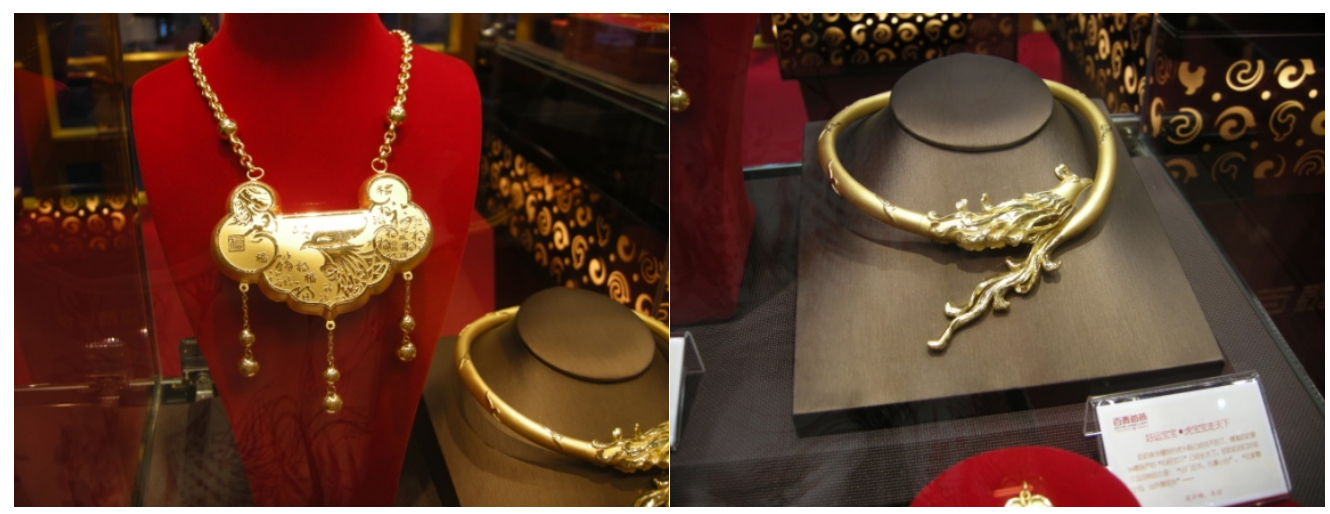

Figure 4 Shenzhen Jewelry Festival

In addition, aesthetic education plays an important role in the training of consumer groups. Since the hot of aesthetics in 1980s, China has been in the middle for more than 20 years. This is exactly the 20 year of China's economic takeoff, and the rise of the economy will inevitably lead to the craze of luxury goods, which is also common in the history of Western and Japanese countries. Today, China has surpassed the United States as the world's second largest consumer of luxury goods. Luxury goods manufacturers from all over the world are also optimistic about China's huge 
market. The flagship stores of each brand are also in the first line of Chinese cities. So large-scale expansion makes fashion and luxury infiltrate into the life of the general public in China. Foreign luxury can seize the heart of young people so quickly, not only because of the historical and cultural connotation of its brand, because we China is the least lack of historical and cultural accumulation. It's not just the Chinese elements in its design, because no one knows China better than we do. The more important reason should be its strong symbolism and the satisfaction of popular mentality, while satisfying self esteem and showing wealth and status. The international luxury brand has a subtle influence on the consumer group from the concept of life. People are obsessed with these design fanaticism, and the symbolic meaning of their symbols has gone beyond the commodity itself. Ordinary small middle class or younger white-collar workers are not alone in order to buy a big new brand. The reason for this phenomenon is due to the rapid increase of national income and the immaturity of consumer psychology. On the other hand, the country's aesthetic education is not enough. While we have forgotten the life aesthetics of the nation, the aesthetic concept of the consumption of luxury goods all over the world has entered all aspects of our life, making us involuntarily produce impulsive imitation. We have lost the understanding and judgement of beauty, and are totally engaged in a totally imitative imitation. The absence of aesthetic education not only affects the development of national design, but also affects people's attitudes and ways of life in a more profound way.

\section{The Influence of College Education on Jewelry Design}

Colleges and universities are the key to guide the design of jewelry and the cultivation of talents' aesthetic education. With the emphasis on talents in various regions, the importance of the school's personnel output has gained more and more attention from enterprises, and the connection between enterprises and schools has become increasingly close. Under the platform of the government, many enterprises and schools have launched more in-depth cooperation to jointly build a scientific, technological and innovative way of production, learning and research. At the early stage of the cooperation and development of enterprises, only students go out to school and take part in a series of practical learning activities in enterprises. Today, this relationship has changed, and enterprises have begun to stabilize their feet in the campus, and set the R \& D base of enterprises on campus. This brings new and greater opportunities to the development of local universities and the incubation of talents. In order to adapt to this change and better serve the local economy, Shenyang University has made a series of reform measures in the teaching system. Like the public art department of Academy of Fine Arts, a number of enterprises in Shenyang and the province have been fully investigated in the formulation of talents training objectives. To grasp the aorta of enterprise development, we must persist in taking the needs of enterprises as the starting point, and vigorously and efficiently train talents needed by enterprises.

\section{Conclusion}

At the same time, the enterprise project is also brought into the classroom. In the professional teaching of grade three of Academy of Fine Arts, the teacher introduced the enterprise project into teaching, and worked together with the enterprises to perfect the curriculum system. This greatly stimulates the creative enthusiasm of the students, and makes the students' creative expression no longer an absolute concept and simple emotional expression, more and more attention to practicality and processability, and the application value of the design is obviously improved. The implementation of this method eliminates the training period from graduation to effective service for enterprises. When students are in school, they will be able to complete the personnel training plan required by the enterprises. After graduation, the students can make seamless connection with the customized enterprises. In addition, we should give full play to the advantage of the powerful scientific research force in the University in light of the difficulties encountered in the development of some enterprises. Let the R \& D backbone of the University and the technical personnel of the enterprise form a scientific research group to form complementary advantages of scientific research 
and technology. This different teaching mode in the past has made schools and enterprises move towards wider space for development.

\section{References}

[1] Kang H, Okazaki S, Abelmann N, et al. Redeeming Immigrant Parents: How Korean American Emerging Adults Reinterpret Their Childhood. [J]. Journal of Adolescent Research, 2015, 25(3):441-464.

[2] Song P, Fu Z, Liu L, et al. printing 3D objects with interlocking parts [J]. Computer Aided Geometric Design, 2015, 35(C):137-148.

[3] Yep J, Brown M, Fagliarone G, et al. Influential Players in Twitter Networks of Libraries at Primarily Undergraduate Institutions [J]. Journal of Academic Librarianship, 2017, 43(3):193-200.

[4] Farmer F. Adjusted Margin: Xerography, Art, and Activism in the Late Twentieth Century, by Kate Eichhorn[J]. Modernism/modernity, 2017, 24(1):1-3.

[5] Gupta P, Hasan R, Kumar U. What Constrains Indian Manufacturing? [J]. Indian Council for Research on International Economic Relations New Delhi Working Papers, 2015, 120(211):45--86.

[6] Steinlechner S, Antrekowitsch J. Potential of a Hydrometallurgical Recycling Process for Catalysts to Cover the Demand for Critical Metals, Like PGMs and Cerium [J]. JOM, 2015, 67(2):1-6.

[7] Usapein P, Chavalparit O. Evaluating the performance of 3R options to reduce landfill wastes using the 3R indicator (3RI): case study of polyethylene factories in Thailand [J]. Journal of Material Cycles \& Waste Management, 2015, 17(2):303-311.

[8] Marianov V, Eiselt $\mathrm{H}$ A. On agglomeration in competitive location models [J]. Annals of Operations Research, 2016, 246(1-2):31-55.

[9] Lina Z, Zhihong L. A improved method for teaching system innovation design of physical education major in colleges based on flipped classroom [J]. Revista De La Facultad De Ingenieria, 2017, 32(9):630-635. 